\title{
ADDITIONAL RECORDS OF THE GENUS Acropimpla Townes (Hymenoptera: Ichneumonidae: Pimplinae) FROM VIETNAM AND AN UPDATED KEY TO SPECIES
}

\author{
Pham Thi Nhi
}

Institute of Ecology and Biological Resources, VAST

Received 10 August 2020, accepted 30 September 2020

\section{ABSTRACT}

Two species of the genus Acropimpla, viz. A. bicarinata (Cameron) and A. uchidai (Cushman), are recorded for the first time from Vietnam. An updated, illustrated key to all eight Vietnamese species of Acropimpla is provided.

Keywords: Ichneumonidae, new records, parasitoids, taxonomy.

Citation: Pham Thi Nhi, 2020. Additional records of the genus Acropimpla Townes (Hymenoptera: Ichneumonidae: Pimplinae) from vietnam and an updated key to species. Academia Journal of Biology, 42(4): 17-24. https://doi.org/10.15625/2615-9023/v42n4.15354

*Corresponding author email: ptnhi2@yahoo.com

(C2020 Vietnam Academy of Science and Technology (VAST) 


\section{INTRODUCTION}

Acropimpla Townes, 1960 is a moderately large genus of the tribe Ephialtini (Ichneumonidae: Pimplinae), with fourty five currently recognized species. The species richness of this genus is highest in the Oriental region (thirty nine species) (Gupta \& Tikar, 1976; He et al., 1996; Liu et al., 2010; Pham et al., 2011; Liu \& He, 2013; Varga \& Reshchikov, 2015; Yu et al., 2016); no species are known from the Neotropical region (Yu et al., 2016).

In Vietnam, the first synopsis of the genus Acropimpla was provided by Pham et al. (2011), in which a total of six species were recorded from the country, viz.: $A$. hapatiae (Rao), A. lampei Pham, Broad \& Wägele, A. leucostoma (Cameron), A. mucronis Pham, Broad \& Wägele, $A$. phongdienensis Pham, Broad \& Wägele and A. taishunensis Liu, He \& Chen. Based on recent field surveys in the northwest region and the Central Highlands, two further species of this genus are recorded for the first time from Vietnam. An updated key to Vietnamese species of Acropimpla is presented.

\section{MATERIAL AND METHODS}

The specimens examined in this study are deposited in the collection of Department of Insect Systematics, Institute of Ecology and Biological Resources (IEBR), Ha Noi, Vietnam. Other collections refer to in this paper are Senckenberg Deutsches Entomologisches Institut (DEI), Müncheberg, Germany and University Museum of Natural History (OMUNH), Oxford, the United Kingdom. Morphological terminology follows Broad et al. (2018). Digital images of specimens (new records and Figs $2 \mathrm{c} \& 3 \mathrm{a}$ ) were taken with a Leica IC80HD camera attached to Leica M80 stereomicroscope, except habitus photos were taken with a ILCE-500L/WAP2 digital camera attached to Leica M80 stereomicroscope (Figs 1a \& 1h), other illustrated figures were taken with a Nikon Digital Camera DXM 1200 via a stereomicroscope with light-box.

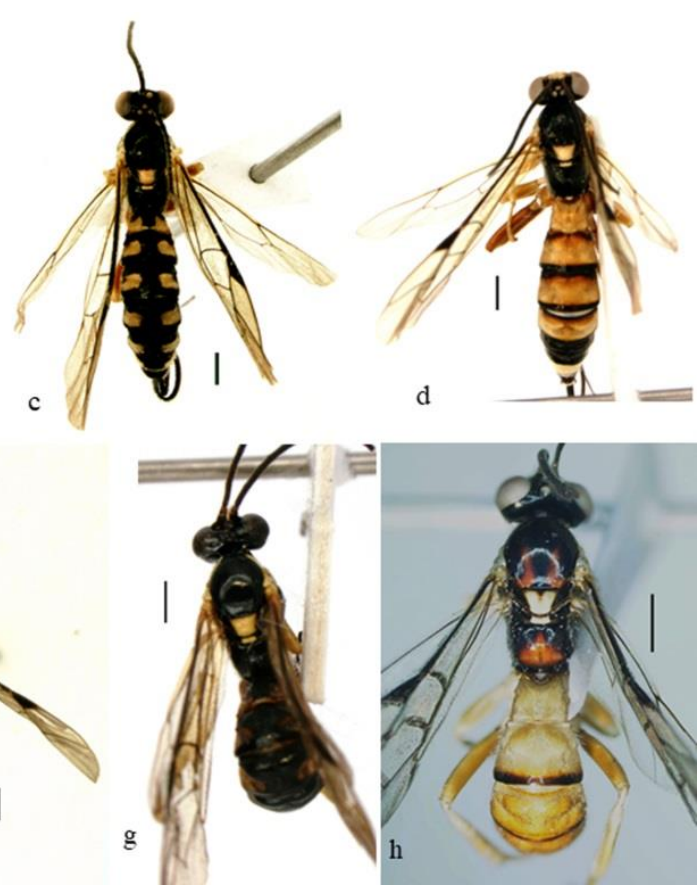

Figure 1. Dorsal view of Vietnamese Acropimpla, $q$ (scale bar $=1 \mathrm{~mm})$ : a. A. bicarinata; b. A. hapaliae; c. A. lampei; d. A. leucostoma; e. A. mucronis; f. A. phongdienensis; g. A. taishunensis; h. A. Uchidai 


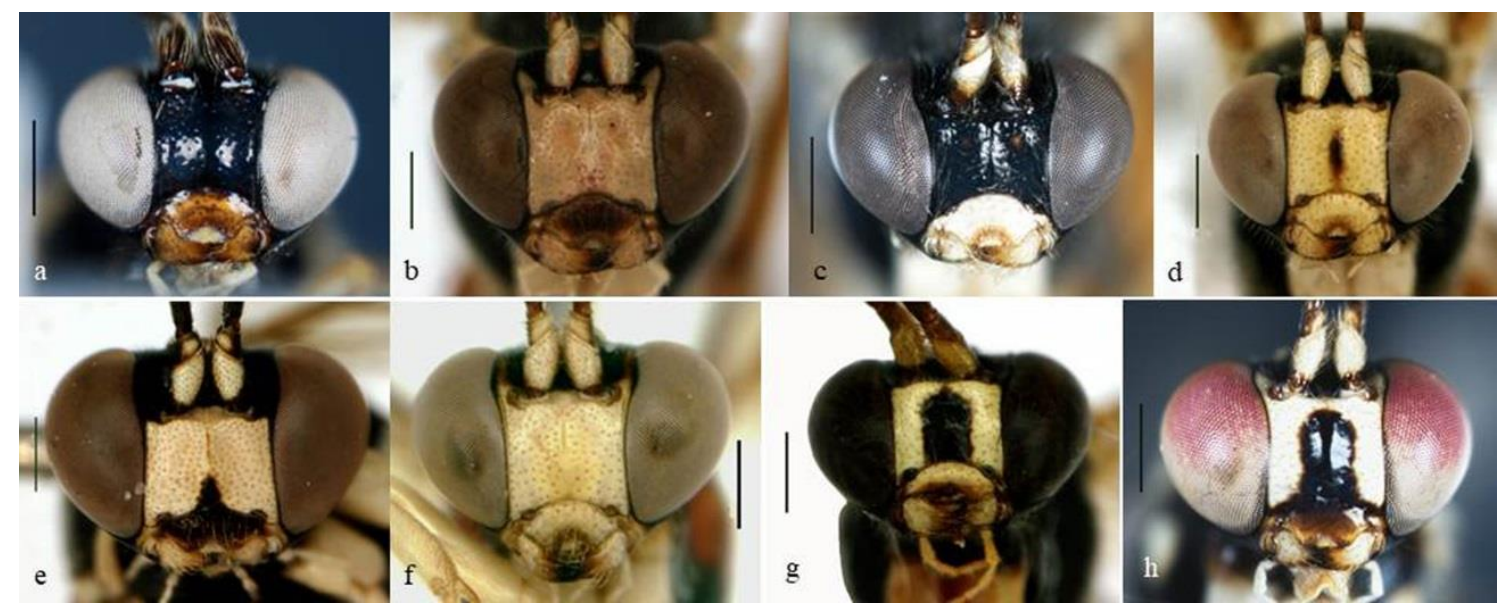

Figure 2. Front view of head of Vietnamese Acropimpla, $q$ (scale bar $=0.5 \mathrm{~mm})$ : a. A. bicarinata; b. A. hapaliae; c. A. lampei; d. A. leucostoma; e. A. mucronis; f. A. phongdienensis; g. A. taishunensis; h. A. uchidai

\section{RESULTS}

\section{Systematics}

\section{Acropimpla Townes, 1960}

Selenaspis Roman, 1910: 191. Name preoccupied by Bleeker, 1858 and by Leonardi, 1898. Type: Hemipimpla alboscutellaris Szepligeti; original designation.

Acropimpla Townes, 1960: 159. Type species: Charitopimpla leucostoma Cameron; original designation.

Diagnosis. Body moderately long; clypeus with median apical notch; malar space short; propodeum short and convex, with or without median longitudinal carina; fore wing with areolet nearly triangular, receiving vein $2 \mathrm{~m}$-cu near apex, vein $2 \mathrm{rs}-\mathrm{m}$ always shorter than vein 3rs-m; hind wing with first abscissa of vein $\mathrm{CU}$ much longer than vein cu-a; first tergite short and wide; second tergite with short, oblique groove cutting off basolateral corner; tergites 3-4 with distinct tubercles; ovipositor straight, tip of dorsal valve in profile a little concave behind nodus, lower valve with oblique ridges apically.

Some Acropimpla species have been known to parasitize a variety of Microlepidoptera, especially Pyralidae, Thyrididae and Hablaeidae (Gupta \& Tikar,
1976), however no hosts of this genus are recorded from Vietnam.

\section{A checklist of Acropimpla species from Vietnam}

Acropimpla bicarinata (Cameron, 1899): India, Myanmar, Vietnam (Lao Cai Province) (Gupta \& Tikar, 1976; this study).

Acropimpla hapaliae (Rao, 1953): China, India, Myanmar, Thailand, Vietnam (Son La, Phu Tho, Hoa Binh, Nghe An and Dong Nai provinces) (Pham et al. 2011).

Acropimpla lampei Pham, Broad, Wägele, 2011: Vietnam (Dak Lak Province) (Pham et al. 2011).

Acropimpla leucostoma (Cameron, 1907): China, India, Indonesia, Japan, Laos, Myanmar, Sri Lanka, Thailand, Vietnam (Lai Chau, Tuyen Quang, Bac Can, Vinh Phuc, Phu Tho, Hoa Binh, Ninh Binh, Ha Tinh, Thua Thien-Hue, Kon Tum, Dak Lak and Dong Nai provinces) (Gupta \& Tikar, 1976; Pham et al., 2011).

Acropimpla mucronis Pham, Broad, Wägele, 2011: Vietnam (Dong Nai Province) (Pham et al., 2011).

Acropimpla phongdienensis Pham, Broad, Wägele, 2011: Vietnam (Thua Thien-Hue Province) (Pham et al., 2011). 
Acropimpla taishunensis $\mathrm{Liu}, \mathrm{He} \&$ Chen, 2010: China, Thailand, Vietnam (Nghe An Province) (Liu et al., 2010; Pham et al., 2011).

Acropimpla uchidai (Cushman, 1933). China, India, Myanmar, Nepal, Thailand, Vietnam (Lam Dong Province) (Gupta \& Tikar, 1976; Varga \& Reshchikov, 2015; this study).

\section{New country records}

\section{Acropimpla bicarinata (Cameron, 1899)}

Pimpla bicarinatus Cameron, 1899. Mem. Proc. Manchester Lit. Phil. Soc. 43(3): 171. Holotype: + , India: Khasi Hills (OUMNH).

Acropimpla bicarinata: Townes \& Townes (1960), 216(2): 160.

Diagnosis. Face, head and mesosoma entirely black; propodeum with median longitudinal carinae distinct; clypeus yellow; metasomal tergites reddish with posterior black bands (except tergite 1 largely black); ovipositor sheath 1.3 times as long as hind tibia (Gupta \& Tikar, 1976).

Material examined. 19 (IEBR), Lao Cai Province, Hoang Lien National Park, 1832 m, 28.ix.2013, Pham Thi Nhi coll.

Distribution. Previously known from India and Myanmar (Gupta \& Tikar, 1976), this is the first record of the species from Vietnam.

\section{Acropimpla uchidai (Cushman, 1933)}

Charitopimpla uchidai Cushman, 1933. Ins. Matsumurana, 8: 39. Holotype: + , Taiwan: Taihorin (DEI).

Acropimpla uchidai: Townes \& Townes (1960), 216(2): 160.

Diagnosis. Face yellow with black mark centrally, yellow extending up inner orbits to antennal sockets; mesoscutum and propodeum black with reddish markings; propodeum with short stub of median longitudinal carinae; mesopleuron with yellow round spot anteriorly; metasomal tergites reddish yellow with posterior narrow black bands on tergites $2-4$; ovipositor sheath 1.8 times as long as hind tibia.

Material examined. 19 (IEBR), Lam Dong Province, Bidoup-Nui Ba National Park, 1478 m, 27.vii.2017, Pham Thi Nhi coll.

Distribution. Previously known from China, India, Myanmar, Nepal, Taiwan, and Thailand (Gupta \& Tikar, 1976; Varga \& Reshchikov, 2016), it is the first record of the species from Vietnam.

Updated key to Acropimpla species of Vietnam (modified from Pham et al., 2011 and based on the keys of Gupta \& Tikar, 1976 \& Varga \& Reshchikov, 2015).

1. Propodeum without or with a short stub of median longitudinal carina (Fig. 3) ...............2

Propodeum with median longitudinal carina distinctly present (Fig. 4) ........................5

2. Face black with two small yellow spots below antennal sockets (Fig. 2c); metasomal tergites black, with two yellow apicolateral spots (Fig. 1c) [ovipositor sheath 2.3 times as long as hind tibia length]. A. lampei Pham, Broad \& Wägele

Face yellow with or without black mark; metasomal tergites entirely black or black with yellow bands.

3. Face yellow (Fig. 2b); tergites largely black (Fig. 1b); ovipositor sheath 2.6 times as long as hind tibia length. A. hapaliae (Rao)

Face with a median black mark (Figs 2d, 2h); tergites largely reddish yellow (Fig. 1d, 1h); ovipositor sheath shorter, about 1.8-2.2 times as long as hind tibia length.

4. Clypeus blackish (Fig. 2h); mesopleuron with a yellow round spot anteriorly; tergites 2-4 with narrow black bands posteriorly (Fig. 1h). A. uchidai (Cushman)

Clypeus yellow (Fig. 2d); mesopleuron without a yellow spot; tergites 2-4 with anterior and posterior narrow black bands, tergites 5 onwards largely black (Fig. 1h). A. leucostoma (Cameron) 
5. Face entirely yellow (Fig. 2f); ovipositor with distinct constriction subapically (Fig. 5f) [ovipositor sheath 2.3 times as long as hind tibia length]....................................... phongdienensis Pham, Broad \& Wägele Face partly to entirely black; ovipositor without distinct constriction subapically (Figs 5a, $5 \mathrm{e}, 5 \mathrm{~g})$

6. Face entirely black (Fig. 1a); scutellum and postscutellum largely black with narrow brownish yellow markings posteriorly (Fig. 4a); ovipositor sheath 1.3 times as long as hind tibia. A. bicarinata (Cameron)

Face yellow with black mark; scutellum and postscutellum entirely yellow; ovipositor sheath longer.

7. Face with small triangular black mark connecting with black clypeus (Fig. 2e); metasomal tergites reddish with narrow black bands on first tergite basally, on second and third tergites posteriorly (Fig. 1e); ovipositor sheath 2.6 times as long as hind tibia length..... A. mucronis Pham, Broad \& Wägele

Face with wide black mark medially, clypeus yellow (Fig. 2g); metasomal tergites black with yellow apicolateral stripes (Fig. 1g); ovipositor sheath 1.8 times as long as hind tibia length. ..A. taishunensis Liu, He \& Chen

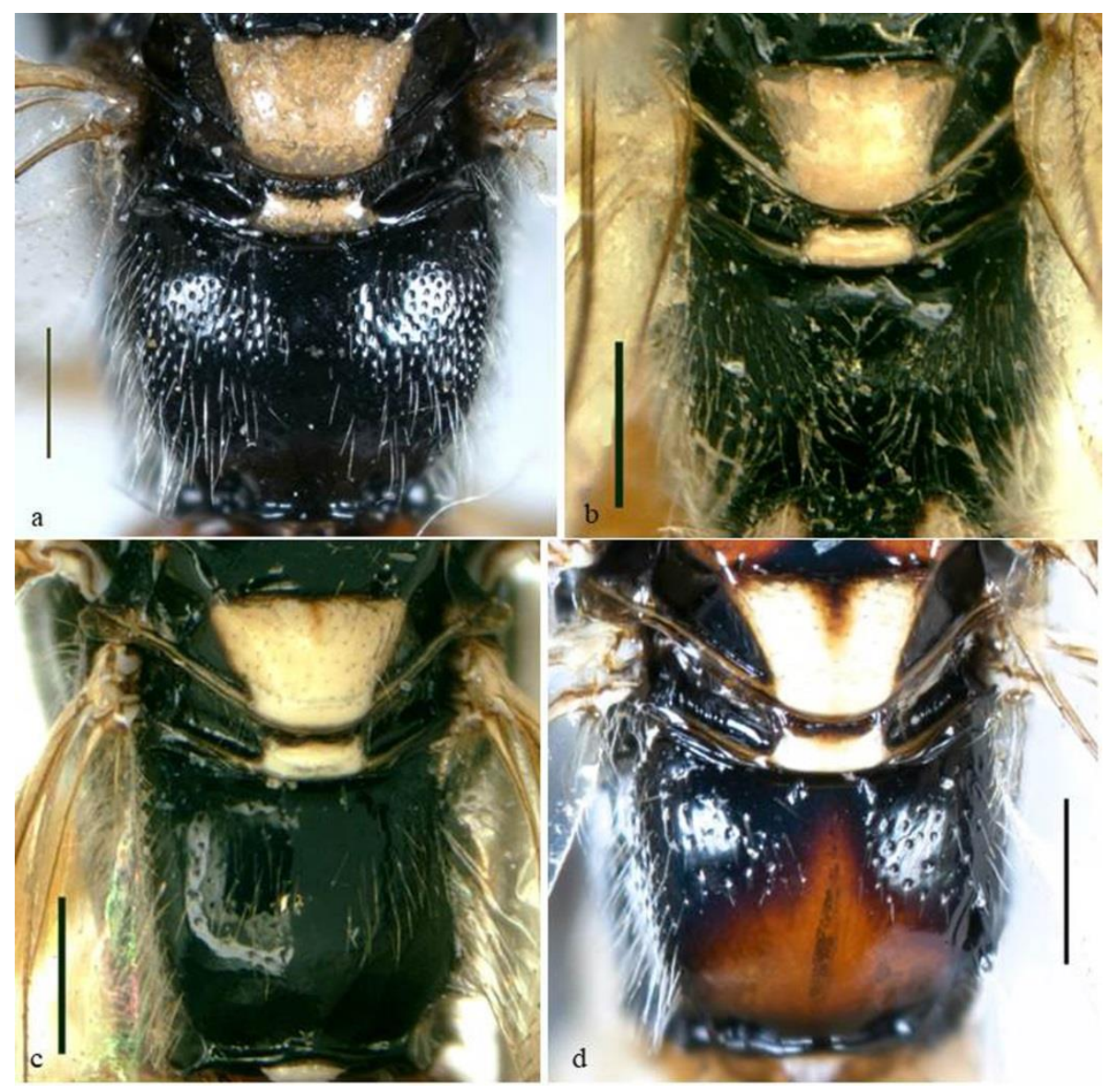

Figure 3. Dorsal view of scutellum, postscutellum and propodeum of Vietnamese Acropimpla, 우 $($ scale bar $=0.5 \mathrm{~mm})$ : a. A. hapaliae; b. A. lampei; c. A. leucostoma; d. A. uchidai 


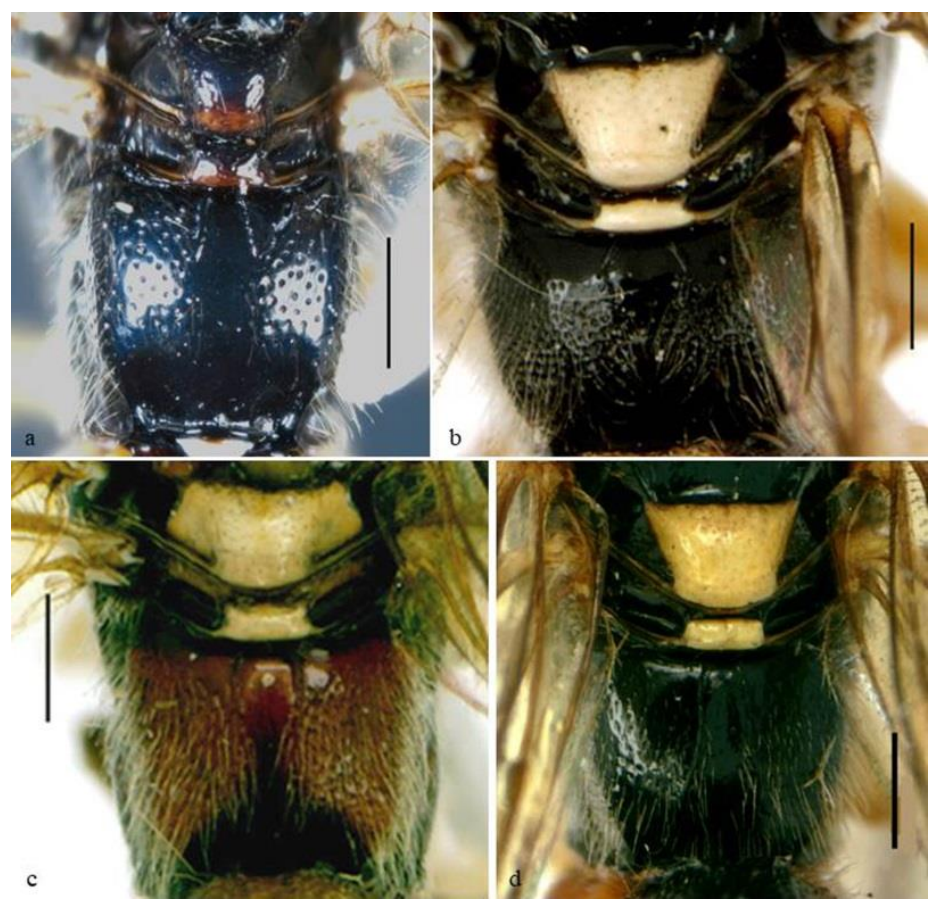

Figure 4. Dorsal view of scutellum, postscutellum and propodeum of Vietnamese Acropimpla, $\rightarrow$ (scale bar $=0.5 \mathrm{~mm}):$ a. A. bicarinata; b. A. mucronis; c. A. phongdienensis; d. A. taishunensis
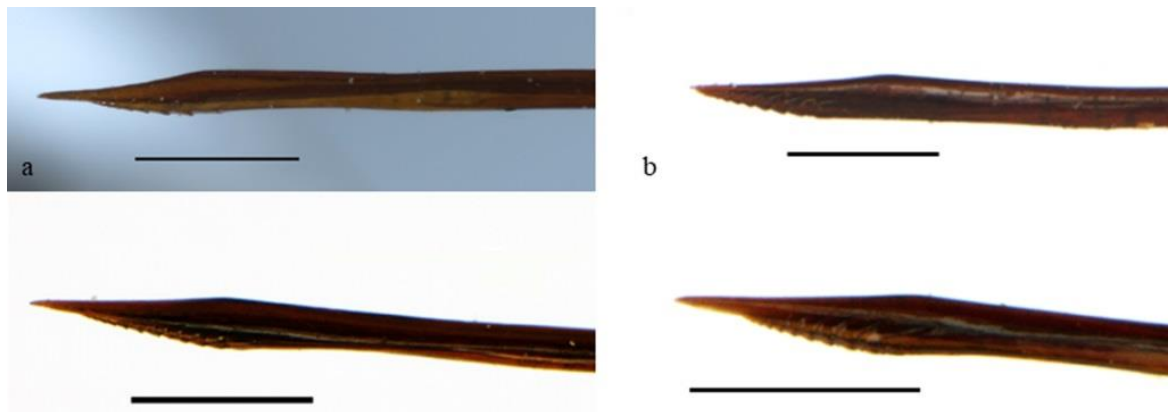

d

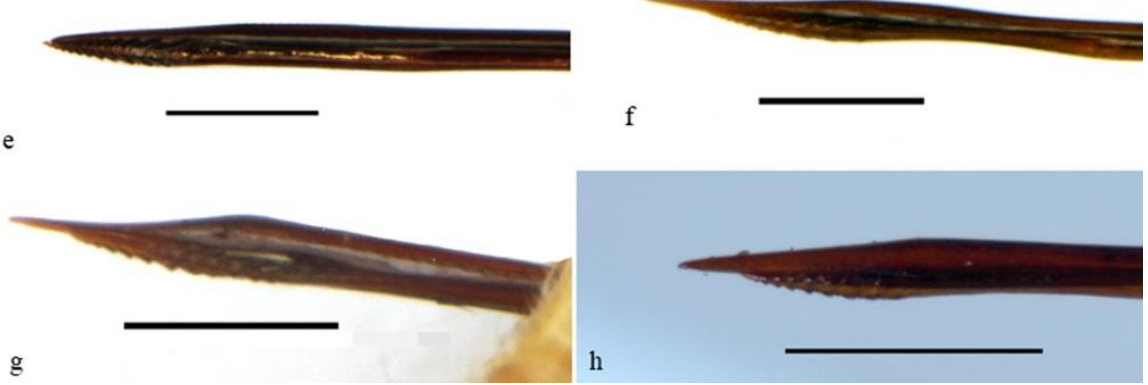

Figure 5. Lateral view of ovipositor tip of the Vietnamese Acropimpla, $q$ (scale bar $=0.5 \mathrm{~mm})$ : a. A. bicarinata; b. A. hapaliae; c. A. lampei; d. A. leucostoma; e. A. mucronis; f. A. phongdienensis; g. A. taishunensis; h. A. uchidai 


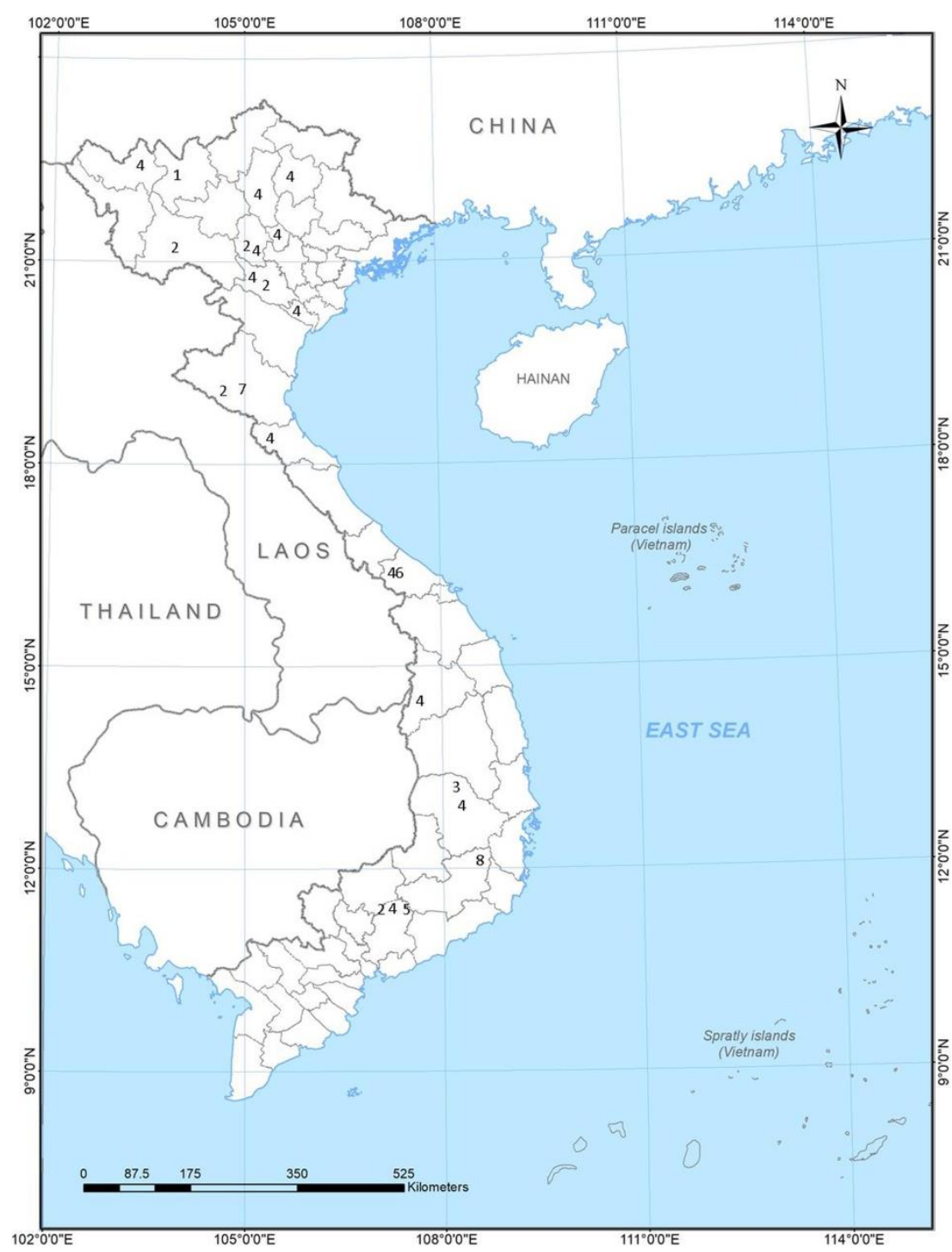

Figure 6. Distribution map of Acropimpla species in Vietnam 1 A. bicarinata 2 A. hapaliae, 3 A. lampei, 4 A. leucostoma, 5 A. mucronis, 6 A. phongdienensis, 7 A. taishunensis, 8 A. uchidai

\section{DISCUSSION}

In neighboring countries of Vietnam, 16 species of Acropimpla have been known from China (He et al., 1996; Liu et al., 2010; Liu \& He, 2013), whereas nine species have recently recorded from Thailand (Varga \& Reshchikov, 2015), one species was reported from Laos (Gupta \& Tikar 1976) and no one is known from Cambodia. Our new records bring the species number of Vietnamese Acropimpla to eight. These new discoveries highlight that the knowledge on the Ichneumonidae fauna of Vietnam, particular in the mountain regions, such as Hoang Lien Ranges and Central Higlands, remains incomplete and that additional field research is warranted.

Hoang Lien Son Range represents the southernmost extention of the Himalayas (Sterling et al., 2006), therefore it is unsurprising that together with Acropimpla uchidai, no less than nine species of the 
subfamily Pimplinae recorded from this mountain range of Vietnam also distribute in India and Myanmar. Our available data showed that up to $56.8 \%$ species of Pimplinae in Vietnam are known from India.

Acknowledgements: This study was partly supported by Ministry of Education and Training (Grant number CT.2019.06.05). The author acknowledge Dr Gavin Broad (Natural History Museum, London, UK) and an anonymous reviewer for comments and suggestions to improve this paper.

\section{REFERENCES}

Broad G. R., Shaw M. R., Fitton M. G., 2018. Handbook for the Identification of British Insects, Vol. 7, Part 12: Ichneumonid Wasps (Hymenoptera: Ichneumonidae): their Classification and Biology. Royal Entomological Society, 424 pp.

Gupta V. K., Tikar D. T., 1976. Ichenumonologia Orientalis or a monographic study of Ichneumonidae of the Oriental Region, Part I. The tribe Pimplini (Hymenoptera: Ichneumonidae: Pimplinae). Oriental Insects Monograph, 1: 1-313.

He J. H., Chen X. X., Ma Y., 1996. Hymenoptera: Ichneumonidae. Economic Insect Fauna of China. Science Press, Beijing, 51: $697 \mathrm{pp}$.

Liu J. X., He J. H., 2013. Description of a new species and a newly recorded species of the genus Acropimpla from China. Acta Zootaxonomica Sinica, 38(3): 586-591.

Liu J. X., He J. H., Chen X. X., 2010. Acropimpla Townes from China (Hymenoptera, Ichneumonidae, Pimplinae), with key to Chinese fauna and descriptions of two new species. Zootaxa, 2394: 23-40.

Pham N. T., Broad G. R., Wägele W. J., 2011. The genus Acropimpla Townes (Hymenoptera: Ichneumonidae: Pimplinae) in Vietnam, with descriptions of three new species. Zootaxa, 2921: $1-12$.

Sterling E. J., Hurley M. M., Le D. M., 2006. Vietnam: A Natural History. Yale University Press, New Haven and London, $423 \mathrm{pp}$.

Townes H., Townes M., 1960. Ichneumonflies of America North of Mexico: 2. Subfamilies Ephialtinae, Xoridinae, Acaenitinae. U.S. National Museum Bulletin, 216(2): 1-676.

Varga O., Reshchikov A., 2015. First record of the genus Acropimpla Townes, 1960 (Hymenoptera: Ichneumonidae, Pimplinae) from Thailand, with descriptions of three new species. Zootaxa, 4013(4): 556-570.

Yu D. S., van Achterberg C., Horstmann K., 2016. Taxapad 2016, Ichneumonoidea 2015. Database on flash-drive. In, Ottawa, Ontario, Canada. 